\title{
Brazilian studies on social determinants of health inequities
}

This Supplement of Cadernos de Saúde Pública/Reports in Public Health on Social Determinants of Health (SDH) features articles on various themes in SDH, with different conceptual perspectives and methodological approaches. The issue includes original studies on mortality, perinatal care, health services utilization, oral health, self-rated health, and violence, among others. The studies were supported by the Department of Science and Technology under the Brazilian Ministry of Health (DECIT/MS), in partnership with the National Research Council (CNPq) and the National Commission on Social Determinants of Health (CNDSS).

The articles in this supplement reflect Brazil's installed capacity to generate evidence in this area, which gained international prominence with the creation of the Commission on Social Determinants of Health (CSDH) by the World Health Organization (WHO) in 2005. The global movement sparked by the CSDH has helped raise the awareness of governments and civil society concerning the importance of social determinants and the need to combat the health inequities generated by them. Brazil joined this movement early-on and with clear determination by creating its own Commission in March 2006. The creation of the CNDSS responds to a tradition in the Brazilian health movement to deepen knowledge on the relations between socioeconomic determinants and health status and to promote concrete actions based on such knowledge.

The research presented in this special issue was conducted in different settings and locations in Brazil, emphasizing the relevance of social inequities for the Brazilian population's health. The findings are consistent with the final report of the CNDSS, entitled The Social Causes of Health Inequities in Brazil, which includes a review of the economic and social transformations that have taken place in the country in recent decades, in addition to an analysis of the advances achieved and the challenges posed by health inequities among Brazilians.

The publication of this Supplement of Cadernos de Saúde Pública/Reports in Public Health was organized by the Center for Studies, Policies, and Information on Social Determinants of Health (CEPI-DSS) at the Sergio Arouca National School of Public Health, Oswaldo Cruz Foundation (ENSP/Fiocruz). The aim of CEPI-DSS is to produce knowledge and information, train human resources, and conduct follow-up and evaluation of policies and interventions in social determinants of health. The Center's lines of work feature the establishment of an Observatory on Social Determinants of Health to monitor health inequities and maintain a portal on SDH (http://determinantes.saude.bvs.br/).

The publication is timely, because this year, 2011, the theme of SDH will gain new emphasis on the global agenda with the World Conference on Social Determinants of Health in October in Rio de Janeiro. This event, organized by WHO, responds to a resolution by the member countries who, at the World Health Assembly in 2009, and after analyzing the report by the $\mathrm{CSDH}$, requested that WHO call a global event to discuss new plans to allow confronting the alarming trends in health inequities by acting on SDH. In keeping with the country's tradition of commitment to the theme, Brazil has the honor of hosting this important event, which mobilizes the political determination of WHO member countries and will design concrete proposals for methods and strategies to combat health inequities. We hope that the current Supplement of Cadernos de Saúde Pública/Reports in Public Health will help deal with this challenge.

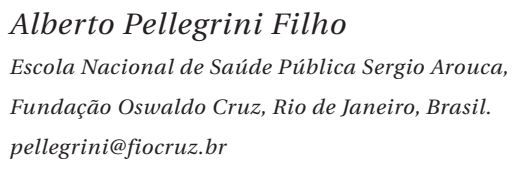

Mario Vianna Vettore

Instituto de Estudos em Saúde Coletiva,

Universidade Federal do Rio de Janeiro, Rio de Janeiro, Brasil. mario@ensp.fiocruz.br 